\title{
ИМПЛЕМЕНТАЦИЯ НОРМ МЕЖДУНАРОДНОГО ПРАВА В ПРАВОВЫЕ СИСТЕМЫ ИСЛАМСКИХ ГОСУДАРСТВ
}

Moxд H. O.

В статье исследован международный (внешний) и национальный (внутренний) механизм имплементации норм международного права. С учётом цивилизационных особенностей изучен порядок включения норм международного права в правовые системы исламских государств. Проанализирована роль исламского права в реализации исламскими государствами международно-правовых обязательств. Сделаны выводы о тесной связи национального права и религии в исламских государствах, что необходимо учитывать при взаимодействии с ними.

Ключевые слова: международное право, имплементация, исламское право, исламские государства.

у статті досліджено міжнародний (зовнішній) і національний (внутрішній) механізм імплементації норм міжнародного права. 3 урахуванням цивілізаційних особливостей вивчено практику включення норм міжнародного права в правові системи ісламських держав. Проаналізовано роль ісламського права в реалізації ісламськими державами міжнародно-правових зобов'язань. Зроблено висновки про тісний зв'язок національного права і релігії в ісламських державах, що необхідно враховувати при взаємодії з ними.

Ключові слова: міжнародне право, імплементація, ісламське право, ісламські держави.

Mokhd N. O. Implementation of the norms of international law in the legal systems of the Islamic states

In the article, a mechanism of international law implementation in national legal order of Islamic states is investigated. In the context of globalization, the interaction of legal systems is intensifying, which means that the relevance of the study of foreign law is increasing, especially its relationship with international law. It is said that the Islamic world is diverse and includes states that have accepted classical Islamic law to varying degrees. Despite the fact that today no state in the world fully follows the Islamic law, its principles and values are still reflected in national legislation, including with regard to the implementation of international law. The definitions of implementation and its features are reviewed. It is said that implementation consists in organizational and legal activities of states undertaken individually or collectively (including within the framework of international organizations), aiming at implementing their international legal obligations in a timely and full manner. Two of its concepts are considered: international (external) implementation and national (internal) implementation. It was revealed that the basis of international implementation is a principle of pacta sunt servanda. This principle is present in Islamic international law (Siyar), too. It is enshrined in the primary sources of Islamic law. National mechanism of implementation consists in the actions of states to realize the norms of international agreements. Due to importance of the issue, the place of an international treaty is fixed in constitutional legislation, as well as special regulatory legal acts. In this regard, to study the implementation of international law into the legal systems of Islamic states, an analysis of the constitutional provisions on the sources of law and international agreements of individual states is necessary. Taking into account civilizational peculiarities, the order of incorporation of international law into the legal systems of Islamic states has been studied. The role of Islamic law in the implementation by Islamic states of international legal obligations is analyzed. Conclusions are drawn about the close relationship of national law and religion in Islamic states, which must be taken into account when interacting with them.

Key words: international law, implementation, Islamic law, Islamic states.

Постановка проблемы и её актуальность. Механизм имплементации норм международного права является одним из важнейших направлений научных исследований многих ученых, среди которых необходимо выделить таких как И.П. Блищенко, А.С. Гавердловский, В.В. Гаврилов, А.И. Зыбайло, И.И. Лукашук, А.И. Минаков, Р.А. Мюллерсон, В.Ю. Калугин. Среди исследователей отсутствует единство взглядов по поводу определения понятия «имплементация», а также сопутствующих категорий, что усложняет процесс теоретического осмысления имплементации норм международного права, в том числе в правовые системы исламских государств. В то же время в условиях глобализации усиливается взаимодействие правовых систем, а значит, усиливается и актуальность исследования иностранного права, особенно его связи с международным. Страны не могут существовать изолировано, и сегодня это особенно наглядно.

Цель статьи - изучить порядок включения норм международного права в правовые системы исламских государств; проанализировать роль исламского права в реализации исламскими государствами международно-правовых обязательств.

Изложение основного материала. Исламский мир - неотъемлемая часть установленного мирового порядка. Представляющие его государства являются членами Организации Объединённых Наций $(\mathrm{OH})$. Они принимают участие как в принятии важнейших политических решений, так и в создании современного международного права путём голосования на заседаниях Генеральной Ассамблеи ООН и её комитетов. Будучи активными акторами на международной арене, они сохраняют связь с исламом, что отражается на национальных правовых системах и процессе имплементации норм международного права.

Следует отметить, что исламское право - это всеобъемлющая система норм, регулирующая как вопросы вероубеждений, так и те, что обычно относятся к сфере ведения светского права, причём как внутреннего, так и внешнего. Исламское право опирается на собственные источники, первичные из которых имеют сакральную природу. Это Священное Писание - Коран и жизнеописание Пророка - Сунна, составляющей частью которой являются хадисы. Исламский мир разнообразен и вклю- 
чает в себя государства, в разной степени воспринявшие классическое исламское право. Несмотря на то, что сегодня ни одно государство мира в полной мере не следует шариату, те или иные его принципы и ценности все ещё отражены в национальном законодательстве, в том числе в отношении имплементации норм международного права.

Международно-правовое регулирование, по верному замечанию И.И. Лукашука, включает в себя не только создание норм, но и их осуществление, иными словами, правотворческую и правоприменительную фазу [1, с. 10]. При этом реализация норм международного права - процесс не менее комплексный и трудоемкий, нежели их создание, и именно от него зависит конечная эффективность международного права.

Реализация международно-правовых норм существенно отличается от реализации норм национального права. Прежде всего, отличия обусловлены субъектным составом обеих правовых систем. Физические и юридические лица, подчиненные национальному правопорядку, образуют горизонтальный правопорядок с центральным органом государственной власти во главе. К субъектам международного права традиционно относят суверенно равные государства и международные межправительственные организации, нации и народы, борющиеся за самоопределение, и государствоподобные образования. Все они формируют горизонтальный порядок. Несмотря на наличие некоторых наднациональных аспектов, он является децентрализованным. Во-вторых, реализация норм национального права состоит, главным образом, в проведении органами государственной власти организационно-оперативных мер, то есть осуществляется с помощью внутреннего институционно-правового механизма. Для реализации же норм международного права требуется принятие мер как на международном, так и на национальном уровнях [2, с. 161].

Сам термин «имплементация» происходит от латинского «implēre», что означает «наполнять», «осуществлять». В самом широком смысле имплементация - это «процесс реализации решения или плана» [3]. В международной правовой плоскости имплементация будет означать «процесс внедрения международных обязательств на практике» [4, с. 539] либо «акт введения в действие нормы международного права в рамках правопорядка государства» [5, с. 4]. Это может быть как единый акт, так и комплекс действий, осуществляемых компетентными органами законодательной, исполнительной или судебной власти на национальном уровне [6, с. 15]. Они будут различными по содержанию и временному периоду, однако все направлены на реализацию положений международного права.

Украинский учёный А.С. Гавердовский в своём труде «Имплементация норм международного права» определяет имплементацию как предпринимаемую индивидуально либо коллективно (в том числе в рамках международных организаций) организационно-правовую деятельность государств, направленную на реализацию принятых ими международно-правовых обязательств своевременно и в полном объеме [7, с. 62]. Данное определение имеет много общего с определением, данным В.Ю. Калугиным. Учёный определяет имплементацию международного права как «деятельность государств по всестороннему, своевременному, полному воплощению в жизнь предписаний, содержащихся в нормах международного права, а также правовое и организационное обеспечение этой деятельности, предпринимаемые ими на внутригосударственном уровне самостоятельно, или на международном уровне индивидуально, или совместно с другими государствами - участниками международных договоров, в том числе в рамках международных организаций» [8, с. 99].

Исходя из изложенных определений, представляется возможным выделить признаки имплементации. Во-первых, это комплексный процесс, а именно организационно-правовая деятельность. Во-вторых, основной субъект имплементации - это государство. Допускается коллективный субъект в виде двух и более суверенно равных государств либо международной организации. В-третьих, цель - полное и своевременное исполнение обязательств, вытекающих из международного правового соглашения, стороной которого является субъект.

Фактически имплементация создаёт связь между правовыми системами национального и международного права. Её можно рассматривать как диалектичное отношение их непрерывного взаимовлияния. С одной стороны, государство, намеревающееся заключить соглашение, соотносит его положения с нормами своего национального права. Считается, что государство не возьмёт на себя обязательства, если их исполнение будет противоречить национальному праву. Так, например, в конституционном законодательстве Королевства Саудовская Аравия (Основной Низам 1992 г.) указывается, что «выполнение настоящих «Основ» не противоречит исполнению договоров и соглашений, заключенных Королевством Саудовская Аравия с другими государствами, международными организациями и учреждениями» (ст. 81). В то же время Низамом определяется, что «Королевство Саудовская Аравия суверенное арабское исламское государство. Его религия - ислам, Конституция - Книга Всевышнего Аллаха и сунна Его Пророка, да благословит его Аллах...» (ст.1), а также «государство защищает права человека в соответствии с исламским шариатом» (ст. 26) [9]. Думается, таким образом государство закрепило «примат религии», в данном случае - национального права. Запрет государства выступать стороной международного договора, содержание которого противоречит Низаму, означает также отказ от международных актов, противоречащих шариату.

С другой стороны, имплементация, какую бы форму она ни имела, изменяет национальное право. Это может происходить с нарушением его целостности, то есть отменой норм, внесением изменений, принятием новых нормативно-правовых актов либо прямым включением международного нормативно-правового акта в систему национального права. Данный процесс не имеет строгих временных рамок, поскольку даже после проведения необходимых правовых процедур по включению конкретной нормы международного права во внутреннее право она будет учитываться при проведении дальнейшей законотворческой деятельности государства. Так, членство в ООН и подписание Всеобщей декларации прав человека 1948 г. нашло отражение в Конституции Исламской Республики Афганистан 2004 г. В ней прямо закреплена обязанность «соблюдать Устав ООН, межгосударственные соглашения, а также международные договоры, к которым присо- 
единился Афганистан, и Всеобщую декларацию прав человека» (ст. 7) [10].

Хотя имплементация подразумевает под собой, главным образом, «действия государств», это не отменяет роли самого международного права в рассматриваемом процессе, из-за чего выделяют международный и национально-правовой механизм имплементации. Международно-правовой, или внешний механизм имплементации обеспечивается собственно нормами международного права.

Основой международно-правового механизма имплементации является один из базовых принципов международного права - «расta sunt servanda», что с латыни переводится как «договоры должны исполняться». Сформировавшийся ещё в обычном праве принцип pacta sunt servanda является общим принципом международного права, а, как известно, «общие принципы международного права, признанные цивилизованными нациями», - один из источников международного права, которые применяет Международный Суд $\mathrm{OOH}$ в решении переданных ему споров (Ст. 38 Статута Международного Суда) [11]. Нормативное закрепление данный принцип получил в Венской конвенции о праве международных договоров 1969 г. Ст. 26 определяет принцип pacta sunt servanda как обязательность каждого действующего договора для его участников, а также необходимость его добросовестного исполнения [12]. Трудно переоценить значимость принципа pacta sunt servanda для международного правопорядка, отношения между субъектами которого строятся на согласии, устном либо письменном. Без признания обязанности его исполнения наступил бы хаос.

В исламе соблюдению договоров уделяется особое внимание. Об этом свидетельствуют Сунна и Коран, призывающие людей к соблюдению обещаний и порицающие обман в любой форме. В первом аяте суры «Трапеза» сказано: «О те, которые уверовали! Будьте верны обязательствам...» [13, 5:1]. Используемое в данной суре арабское слово «'aqd» означает обязательства трёх видов: обязательства перед Богом, обязательства человека перед самим собой и обязательства, вытекающие из соглашения с другими людьми, юридическими лицами, а также государствами. Известны слова Мухаммада, Пророка ислама: «Тот, кто верует в Аллаха и в наступление Дня суда, должен соблюдать данные им обещания»; «Обещание верующего, данное им брату по вере, подобно обету, хотя и не имеет искупления. Если кто-либо нарушит своё обещание, то он пойдёт против Аллаха и этим заслужит Его гнев» (Аль-кафи, Мухаммад Кулейни) [14, с. 100]. Соблюдение договора является обязательным в отношении всех людей, а не только в отношении единоверцев: «Всевышний <...> не позволил нарушать договор, независимо от того, с кем он был заключён - с праведником или грешником» - так передаются слова имама Садика (Аль-кафи, Мухаммад Кулейни) [14, с. 101].

Принцип pacta sunt servanda является частью Сийара - международного исламского права. Согласно данной отрасли исламского права обязательства должны быть исполнены, даже если это невыгодно для мусульманина. Исламскому государству запрещено изменять или расторгать международный договор односторонним действием даже в состоянии войны. Только при невозможности исполнения договора (rebus sic stantibus) и форс-мажорных обстоятельствах допускается признание его временно недействительным [15, с. 44].

Примечательно, что к доктрине pacta sunt servanda общались в арбитражном процессе между Саудовской Аравией и нефтяной компанией «ARAMCO». В решении по данному делу было указано, что исламское право «не проводит различия между соглашениями, договорами публичного или административного права и договорами между частными лицами», а также что «исламская судебная практика никогда не признавала, что договор, заключенный правительством, должен толковаться в его пользу» [16]. Так, pacta sunt servanda действующий принцип как для международного права, так и для Сийара.

Национально-правовой или внутренний механизм имплементации определяется субъектами национального права и осуществляется в его рамках. Нет сомнений в том, что эффективность международного права напрямую зависит от действий государств, направленных на имплементацию его положений в национальное законодательство. Учитывая важность данного вопроса, нормативное закрепление места международного договора находится в конституционном законодательстве, а также специальных нормативно-правовых актах. В связи с этим для исследования имплементации норм международного права в правовые системы исламских государств необходим анализ конституционных положений об источниках права и международных соглашениях отдельно взятых государств. В современном мире наблюдается конституционализация правовых систем. По верному замечанию Х. Бехруза, конституции исламских государств представляют собой «результат достигнутого компромисса между различными силами традиционного и реформаторского характера, этапом становления современного типа конституционализма» [17].

И все же главным камнем преткновения в реализации норм международного права является не несовершенство законодательной техники, а цивилизационные противоречия, вызванные социокультурными особенностями государств и их правовых систем. Достаточно часто во главу угла ставится национальный фактор, а для исламских государств - наиболее значимый - религиозный. В правовых границах исламских государств верховенство международного права ограничивается официальной религией, которой отведена особая роль. В этих государствах могут применяться лишь те нормы международного права, которые не вступают в ценностный конфликт с основными положениями и принципами исламского права, что нормативно закреплено в ряде конституций.

В Конституции Йеменской Республики 1991 г. подчеркивается этническая и религиозная идентичность народа: «...Йеменский народ - часть арабской нации и исламского мира». Ислам в Йемене провозглашен государственной религией (ст. 2), а шариат - главным источником законодательства (ст. 3) [18]. Приверженность Конституции Йемена исламским ценностям прослеживается и в других статьях. Особенно остро религиозный вопрос стоит в тех сферах, что связаны с занятием высших государственных постов.

Международное право, однако, занимает почетное место в правовой системе Йемена. В ст. 5 Конституции сказано: «Йеменская Республика подтверждает 
свою приверженность Уставу ООН, Всеобщей декларации прав человека, Уставу Лиги арабских государств и общепризнанным нормам международного права» [18]. Так, уважение к «западному» международному праву идет вместе с почтением к одной из ключевых региональных организаций с исламским уклоном - Лиге арабских государств. Думается, данная норма Конституции наглядно демонстрирует приоритетность норм, существующую в государстве, то есть результаты исламского международного правотворчества не менее важны, нежели светские международно-правовые акты.

Относительно процедуры имплементации Конституция также содержит ряд норм. Так, международные политические и экономические договоры и конвенции общего характера, «и особенно относящиеся к вопросам обороны, создания союза, установления перемирия, заключения мира и решения вопроса о границах, а также те, которые включают выполнение финансовых обязательств, или для реализации которых необходимо принимать специальные законы», проходят процедуру ратификации, которую осуществляет Палата представителей (ст. 91) [18].

Нормы, посвящённые исключительно международному праву и его статусу в национальной правовой системе, в Конституции Сирийской Арабской Республики 2012 г. отсутствуют. Некоторые тенденции можно выявить вследствие анализа конституционных норм, содержащих полномочия органов государственной власти. Так, президент Сирии, в соответствии со ст. 107, «заключает международные соглашения и договоры и отзывает их в соответствии с нормами Конституции и правилами международного закона». «Одобрение международных соглашений и конвенций касательно безопасности государства <...> или противоречащих нормам действующих законов и требующих нового законодательства, которое должно вступить в силу», осуществляет Народная Ассамблея (ст. 75) [19]. Здесь можно предположить, что в сирийской национальной правовой системе нормы международного права равноценны нормам конституционным, а значит, обе правовые системы пребывают в состоянии равенства.

Согласно ст. 4 Конституции Исламской Республики Иран 1979 г. все государственные законы и установления (гражданские, экономические, финансовые, культурные, административные, уголовные, военные и др.) должны основываться на исламских нормах, и эта норма является приоритетной по отношению к другим статьям Конституции либо другим нормативно-правовым актам государства. Решение же относительно соответствия правового акта положениям Исламского права выносят факихи Совета по охране Конституции и исламских норм (ст. 4). Согласно ст. 77 Конституции Ирана «договоры, соглашения и иные международные документы должны проходить ратификацию в Меджлисе исламского совета» - законодательного органа власти, состоящего из избираемых тайным прямым голосованием представителей народа (ст. 62). После ратификации Меджлисом Исламского Совета договоры и соглашения иранского правительства с другими государствами и договоры, относящиеся к международным организациям, подписываются президентом или его законным представителем (ст. 125) [20]. Так, международный договор признается Ираном, если, во-первых, по своему содержанию он соответствует положениям исламского права и другим требованиям, как, например, отсутствие угрозы независимости, что выражается в его ратификации Меджлисом Исламского Совета. Во-вторых, такой международный договор подписывается высшим официальным лицом после лидера страны - президентом либо его законным представителем.

Выводы. При имплементации международно-правовых норм в правовых системах исламских государств необходимо учитывать не только природу этих норм, но и особенности исторически сформировавшейся правовой системы, напрямую связанные с ее религиозным характером. Исламскими государствами, признающими ислам официальной религией, наравне с признанием международного права выдвигается требование его соответствия принципам и ценностям шариата. Думается, это следует учитывать как при анализе международной правотворческой деятельности исламских государств, так и при выстраивании отношений с исламским миром.

\section{Литература}

1. Лукашук И.И. Международно-правовое регулирование международных отношений (системный подход). Москва : Международные отношения, 1975.

2. Каримов М.М. Современные подходы к определению понятия «имплементация международно-правовых HOpM». URL: http://www.lib.krsu.edu.kg/uploads/files/ public/2030.pdf

3. A. Stevenson (ed), Oxford Dictionary of English. 3rd edn. OUP. Oxford, 2010.

4. Raustiala K., Slaughter A.-M. 'International law, international relations and compliance', in: W. Carlsnaes, Th. Risse and B.A. Simmons (eds), Handbook of international relations. Sage Publications. London, 2002. P. 538-558.

5. Jacobson H.K., Brown E. Weiss. 'A framework for analysis' in: Idem (eds), Engaging countries. Strengthening compliance with international environmental accords. MIT Press. Cambridge MA, 1998. P. 1-18.

6. Beenakker E.B. The implementation of international law in the national legal order : a legislative perspective. URL: https: / /openaccess.leidenuniv.nl/bitstream/handle/1887/ 63079/01.pdf?sequence $=3$

7. Гавердовский А.С. Имплементация норм международного права. Киев : Вища школа. Головное изд-во, 1980.

8. Калугин В.Ю. Механизм имплементации международного гуманитарного права : монография. Минск : Светоч, 2003. $336 \mathrm{c}$.

9. Основной Низам (Положение) Королевства Cayдовская Аравия (Пер. на русск. яз.). URL: https:// saudianews.ru/?page_id $=2589$

10. The Constitution of the Islamic Republic of Afghanistan. URL: http://www.afghanembassy.com.pl/afg/ images/pliki/TheConstitution.pdf

11. Статут Международного Суда. URL: https:// www.un.org/ru/icj/statut.shtml

12. Венская конвенция о праве международных договоров. URL: https://www.un.org/ru/documents/decl_conv/ conventions/law_treaties.shtml

13. Коран: перевод смыслов и комментарии Кулиева Э.P. URL: https://quran.com.ua/downloads/quran-ruskuliev.pdf

14. Баешев А. Имам Али ибн Аби Талиб. Исламская нравственность. 2011. 328 с.

15. Sara McLaughin Mitchell, Emilia Justyna. Domestic Law goes global: Legal Traditions and International 


\section{Проблеми становлення правової демократичної держави}

Courts. Cambridge University Press, 2011. URL: https:// books.google.com.ua/books?id=t_iQyBjbFRQC\&pg=PA44\&lp $\mathrm{g}=\mathrm{PA} 44 \& \mathrm{dq}=$ pacta+sunt+servanda+islamic+states\&source $=\mathrm{b}$ \& nE1kA\&hl=ru\&sa $=X \& v e d=2$ ahUKEwjA3_X4jLDpAhWpmlsKHf 64DAIQ6AEwBXoECAYQAQ\#v=onepage $\bar{q} q=$ pacta\%20 sunt $\% 20$ servanda\%20islamic\%20states\& $f=$ false

16. ARAMCO-Award, ILR 1963, at 117 et seq. URL: https://www.trans-lex.org/260800/_/aramco-award-ilr1963-at-117-et-seq/

17. Бехруз X. Влияние международного права на национальное законодательство Исламских государств : VII Міжнародна науково-практична конференція «Міжнародне право: de lege praeterita, instante, future» (8 грудня
2017 р.) ; Міжнародний гуманітарний університет. Одеса, 2017. С. 16-19.

18. Конституция Йеменской Арабской Республики. URL: https: / / worldconstitutions.ru/?p=81

19. Конституция Сирийской Арабской Республики. URL: https: / / worldconstitutions.ru/?p=459

20. Конституция Исламской Республики Иран. URL: https: //worldconstitutions.ru/?p=83

Моху H. O., аспирант кафедры международного и европейского права Национального университета «Одесская юридическая академия» 